\title{
Growth retardation in side shoots of Brussels sprout plants ${ }^{1}$
}

\author{
H. G. Kronenberg
}

Department of Horticulture, Agricultural University, Wageningen, the Netherlands

Received: 18 February 1971

\section{Summary}

Bud cuttings were taken from out door grown Brussels sprout plants from 19 May till 6 October 1969 . These cutting plants were grown in continuous light at $15^{\circ} \mathrm{C}$. Stem length measured after 12 weeks decreased with time in the first 7 series and increased in the last 4 . This decreasing growth activity coincides with the decreasing activity of plants in the field, resulting in the formation of sprouts. Long side shoots can therefore originate only early in the season.

\section{Introduction}

Young Brussels sprout plants, grown from bud cuttings taken in the way described earlier (Kronenberg, 1969 b), show a normal growth pattern. These cuttings were obtained from pot grown plants which were brought from the open into a $15^{\circ} \mathrm{C}$ greenhouse in the end of September and kept there during the winter. From February onwards cuttings were taken.

Normally axillary buds on sprout plants in the field develop into sprouts only from August to November.

In 1968 however sprout plants from cuttings, planted in the open the 10th of May, showed a remarkable early development of axillary buds. The first buds grew into real side shoots instead of sprouts. Later in the season loose sprouts ('roses') developed instcad of real side shoots. Still later normal sprouts were formed (Fig. 1). It seems possible therefore that sprout plants can initiate 'normal' and short side shoots, which aspect ras been analysed more extensively in 1969 and 1970 .

\section{Materials and methods}

The cutting plants used in the experiments were taken from vegetatively propagated p!ants. To make these plants, bud cuttings were taken on 3 February 1969, inserted in moss-peat and rooted at $21^{\circ} \mathrm{C}$. The young plants were potted on 3 March and brought in the open on 15 April. From 19 May onwards, every fortnight cuttings were taken from the plants until 6 October. At the first date the leaves were big enough to be used; the last date was determined by the fact that otherwise flowering started immediately. In this way 11 series were obtained, 10 plants in each one. Although an attempt was made to choose all the cuttings with leaves of the same size, the average 

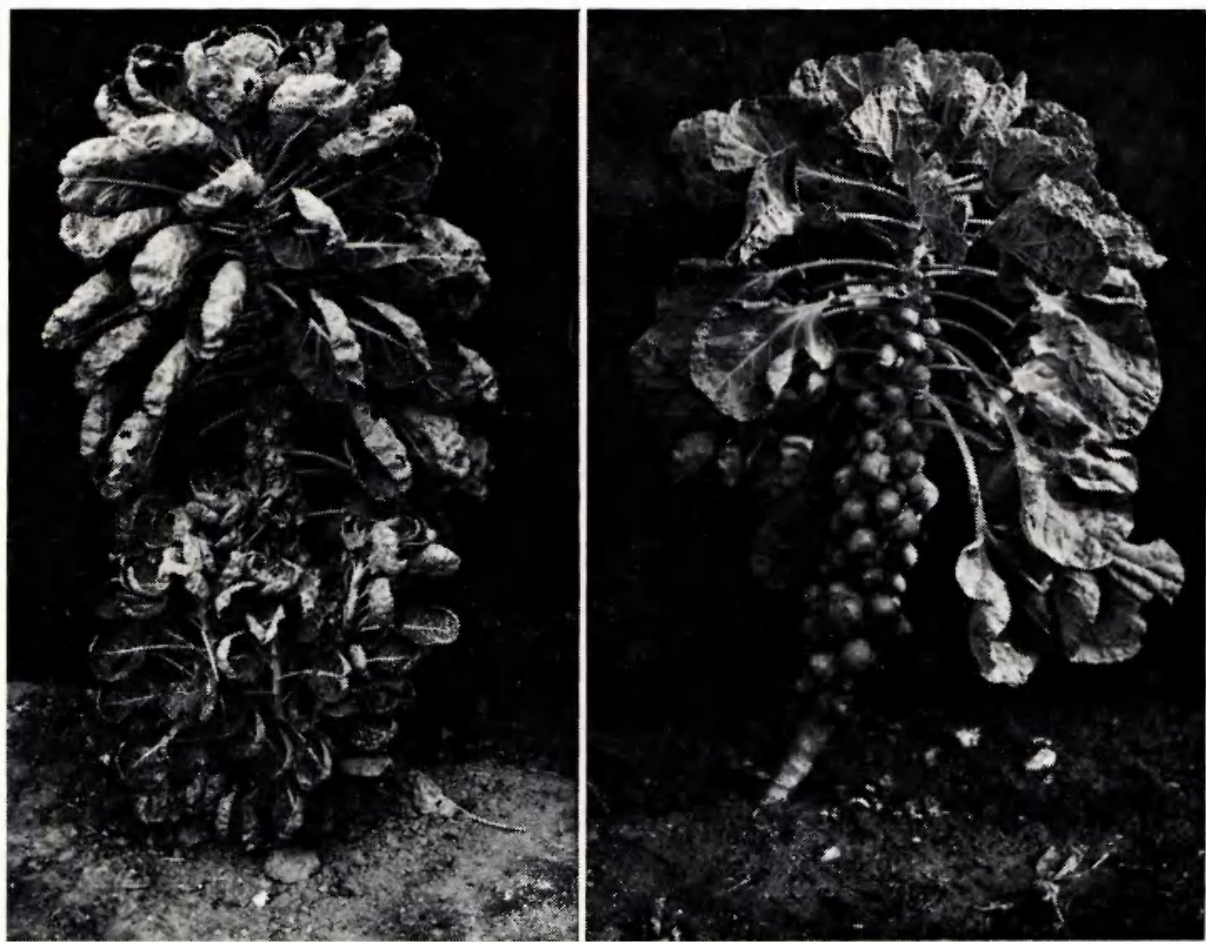

Fig. 1. Sprout plants cv. 'Sandra' photographed on 28 October 1970.

Left: a vegetatively propagated plant with Iong side shoots.

Right: a plant from seed with sprouts.

leaf surface varied between $70 \mathrm{~cm}^{2}$ (in the earlier and later series) and $95 \mathrm{~cm}^{2}$. All cuttings were rooted in moss-peat at $21^{\circ} \mathrm{C}$ and potted after 4 weeks. The potted plants were brought into a $15^{\circ} \mathrm{C}$ growth room of the phytotron of the Department of Horticulture (Doorenbos, 1964) and grown there for 8 weeks under continuous light. After this period plant length was measured. The experiments were repeated in the year 1970 .

\section{Results and discussion}

The results of the experiments in both years were nearly identical. The measurements of 1969 are given in Fig. 2. Young sprout plants from the first series elongate to an average length of $18 \mathrm{~cm}$. The series 1 to 7 show a decline in elongation, after which in the series 8 to 11 plant length increases up to nearly the same length as that in series 1 . The minimum length was $4 \mathrm{~cm}$.

The results given in Fig. 2 are in fair agreement with those obtained earlier (Kronenberg, $1969 \mathrm{~b}$ ): in the beginning of the year young plants obtained from cuttings are ready to elongate.

The behaviour of the plants in the 1968 sprout field is more complicated. On the planting date in 1968 (10 May) plants were about 10 weeks old and already adult (Kro- 


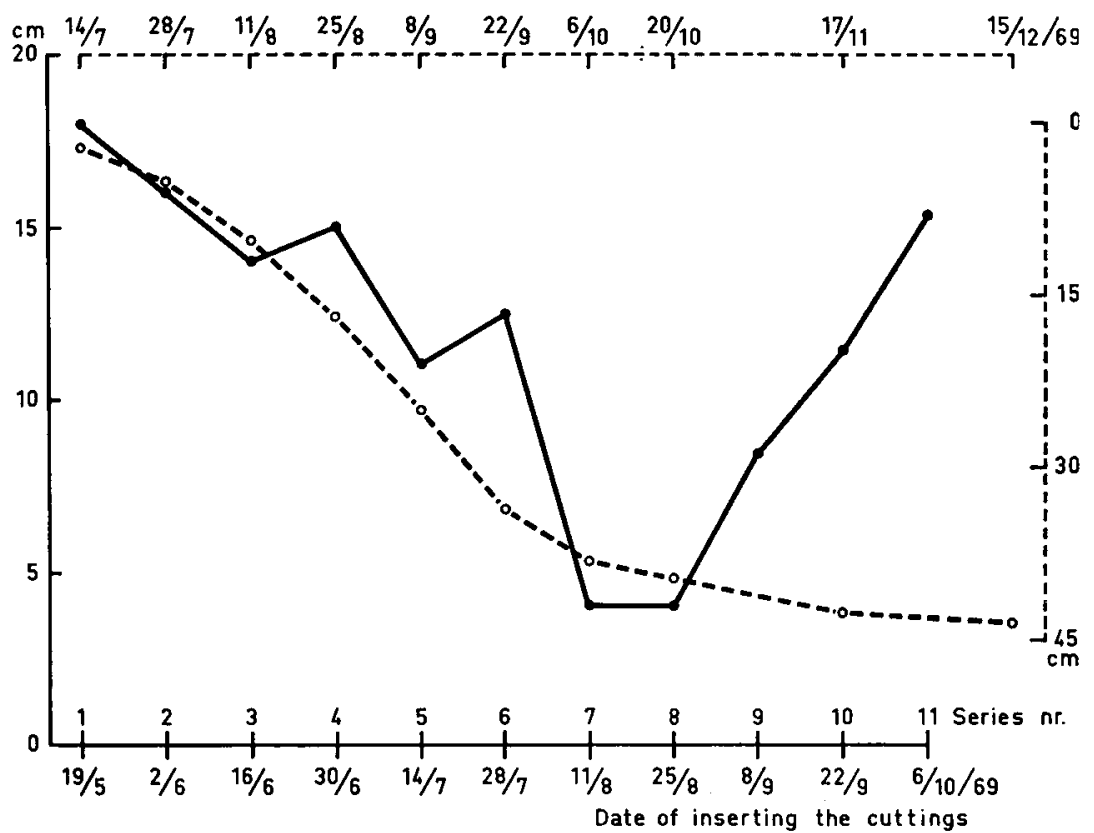

Fig. 2. Length of 12-week-old sprout plants from bud cuttings cv. 'Sandra' (drawn line) and length of a long side shoot (dotted line).

nenberg, 1971). Adultness in sprout plants means another plant shape, a constant ratio of dry weight of leaves and stems and a development of axillary buds (Stokes and Verkerk, 1951). In an early state young vegetatively propagated plants are still able to develop side shoots. Later in the season growth is retarded. So there is a fair resemblance between the facts described from the 1968 sprout field and these shown in Fig. 2 (drawn line). This is demonstrated by the dotted line giving the growth of a long side shoot in 1969. The dates in the top of the graph and those at the bottom differ 8 weeks. This seems acceptable because the young plants from cuttings had to root first before they could grow: they lost 4 of their 12 weeks. The declining disposition to elongate will thus fall from the middle of June to the beginning of October. In the beginning of this period there will be nearly normal elongation, later on no elongation at all. The plants in the field stopped to make normal side shoots and started to make 'roses' and sprouts.

The second part of Fig. 2 has to be considered separately. The cutting plants grew at $15^{\circ} \mathrm{C}$. With the plants in the field the comparable period is from the middle of October to the beginning of December. Kronenberg (1967a) investigated the optimal temperature for sprout growth, which occured at $12^{\circ} \mathrm{C}$. Average temperatures in the Netherlands, however, are $15^{\circ} \mathrm{C}$ in September, $10.4^{\circ} \mathrm{C}$ in October and $5.6^{\circ} \mathrm{C}$ in November. The apparent discrepancy in the second part of the figure therefore is due to suboptimal temperatures in the sprout field.

The above reported results explain also the growth habit of sprouts on generatively propagated sprout plants. Plants are normally sown in the beginning of April. The juvenile phase in this time of the year is estimated $8-10$ weeks. Transplanting causes usually a time of about 2 weeks without length growth. With plants sown early in April 
the juvenile phase will be terminated about the beginning of June. If the plants are big enough then axillary buds will develop. Most time growth of buds starts later. Side shoots will elongate slightly, but the elongation rate will decrease. The first shoots may still grow into 'roses'. Later in the season, however, only real sprouts can be formed. The later in the season the firmer the sprouts will be.

Growers of early sprouts report that sometimes fields have to be cleaned from long side shoots and always from 'roses'. This phenomenon matches very well in the whole picture. In cases where sprout plants are planted early and no loss of 2 weeks occurs after transplanting and if the plants grow a little faster than usual they terminate the juvenile phase early, which results in longer side shoots and 'roses'.

\section{References}

Doorenbos, J., 1964. Het fytotron van het Laboratorium voor Tuinbouwplantenteelt der Landbouwhogeschool. Meded. Dir. Tuinb. $27: 432-437$.

Kronenberg, H. G., 1967a. Probleme bei der einmaligen Rosenkohlernte. SAFA 19: 18-19.

Kronenberg, H. G., 1967b. Vegetatieve vermeerdering van spruitkool. Meded. Dir. Tuinb. 30: $314-315$.

Kronenberg, H. G., 1971. Adultness in cuttings of Brussels sprout plants. Neth. J. Agric. Sci. 19, $000-000$.

Stokes, P. and Verkerk, K., 1951. Flower formation in Brussels sprouts. Meded. LandbHogesch. Wageningen 50: 141-160. 